\title{
Linalool, a plant-derived monoterpene alcohol, reverses doxorubicin resistance in human breast adenocarcinoma cells
}

\author{
RAFFAELLA RAVIZZA, MARZIA B. GARIBOLDI, ROBERTA MOLTENI and ELENA MONTI \\ Department of Structural and Functional Biology, Section of Pharmacology, University of Insubria, \\ Via A. da Giussano 10, 21052 Busto Arsizio, Varese, Italy
}

Received December 12, 2007; Accepted March 28, 2008

DOI: $10.3892 /$ or_00000051

\begin{abstract}
Essential oils from various aromatic plants have been reported to exert chemopreventive and/or antitumor effects. In addition, a number of studies have shown the ability of chemopreventive phytochemicals to increase the sensitivity of cancer cells to conventional anticancer drugs. The success of chemotherapeutic agents is often hindered by the development of drug resistance, with multidrug resistant (MDR) phenotypes reported in a number of tumors, generally involving reduced intracellular drug accumulation due to increased drug efflux by membrane transporters. In the present study, the effects of linalool (LIN), a monoterpene alcohol found in the essential oils from many aromatic plants, on the growth of two human breast adenocarcinoma cell lines, MCF7 WT and multidrug resistant MCF7 $\mathrm{Adr}^{\mathrm{R}}$, were investigated, both as a single agent and in combination with doxorubicin (DOX). The results reported here show that LIN only moderately inhibits cell proliferation; interestingly, however, subtoxic concentrations of LIN potentiate DOX-induced cytotoxicity and pro-apoptotic effects in both cell lines. A significant synergism can be observed in MCF7 Adr ${ }^{\mathrm{R}}$ cells, which may be due, at least in part, to the ability of LIN to increase DOX accumulation and to induce a decrease in Bcl- $\mathrm{x}_{\mathrm{L}}$ levels. In summary, the results of the present study suggest that LIN may improve the therapeutic index of anthracyclines in the management of breast cancer, especially in MDR tumors.
\end{abstract}

\section{Introduction}

The pharmaceutical properties of aromatic plants are partially attributed to their volatile extracts (essential oils), containing a wide variety of active phytochemicals, such as flavonoids, monoterpenes, and polyphenols, among many others (1). In

Correspondence to: Professor Elena Monti, University of Insubria, Section of Pharmacology, Department of Structural and Functional Biology, Via A. da Giussano 10, 21052 Busto Arsizio, Varese, Italy E-mail: elena.monti@uninsubria.it

Key words: linalool, doxorubicin, multidrug resistance, breast cancer recent years, essential oils from many different herbs and phytochemicals derived thereof have been reported to exert chemopreventive and/or antitumor effects through a number of mechanisms (2-4). These observations have suggested a potential use for these compounds as an alternative to chemically designed antineoplastic agents, or as adjuvant treatments (5); however, increasing evidence from in vitro and animal models indicates that combining dietary-derived phytochemicals with conventional antineoplastic drugs is probably the most promising application for these compounds (6). The success of both cytotoxic and targeted chemotherapeutic agents is often hindered by the development of drug resistance, and particularly multidrug resistance (MDR), a condition most commonly involving altered expression/ function of energy-dependent drug transporters belonging to the ABC (ATP-binding cassette) superfamily, leading to reduced intracellular drug accumulation, and/or impairment of one or more steps of the apoptotic signalling cascades (7). Several phytochemicals, including curcumin, indole-3carbinole (I3C), epigallocatechin gallate and resveratrol have been shown to reverse MDR mediated by ABC transporters (8-10).

The present study focuses on the antiproliferative and chemosensitizing properties of linalool (Fig. 1), an acyclic monoterpene alcohol found in the essential oils from many aromatic plants, including lavender (Lavandula officinalis), coriander seeds (Coriandrum sativum) and sweet basil (Ocimum basilicum). Linalool is the main constituent of the volatile extract of Mentha citrata (11), also known as Bergamot mint, original of central and southern Europe and still widely cultivated for its antiseptic and digestive properties. Linalool is used as an additive for processed food and beverages and even more commonly as a fragrance ingredient in cosmetics, toiletries and household detergents (12). Studies on linalool-containing essential oils indicate that this compound possesses antimicrobic, antibacterial and antiviral effects (13-17), as well as anti-inflammatory, analgesic and local anaesthetic activities (18-20). As several plant-derived monoterpenes have been shown to prevent and arrest tumor growth (reviewed in refs. 21-23), recent studies have focused the chemopreventive/chemotherapeutic potential of linalool, with contrasting results (24-26).

In the present study the effects of linalool (LIN) on the growth of two human breast adenocarcinoma cell lines, MCF7 WT and MCF7 Adr ${ }^{\mathrm{R}}$ were investigated; the latter was 


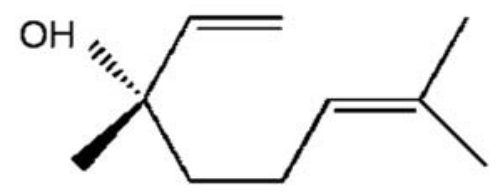

Figure 1. Molecular structure of Linalool.

derived from MCF7 WT cells by continuous exposure to doxorubicin (DOX) and exhibits a typical MDR phenotype, characterized by P-glycoprotein (Pgp or ABCB1, according to the current classification) overexpression and by reduced intracellular drug accumulation $(27,28)$. In addition, the ability of LIN to modulate DOX cytotoxicity in both cell lines was also assessed. The results reported here show that LIN as a single agent has weak antiproliferative effects on MCF WT and $\operatorname{Adr}^{\mathrm{R}}$ cells; however, when subtoxic concentrations of LIN are combined with DOX, the cytotoxic and pro-apoptotic effects of the anthracycline are potentiated in both cell lines. A significant synergy is observed in MCF7 $\mathrm{Adr}^{\mathrm{R}}$ cells exposed to the LIN/DOX combination, which seems to be due, at least in part, to the ability of LIN to increase DOX accumulation, possibly by interfering with Pgp-mediated drug efflux. Determination of the intracellular levels of proteins involved in cell cycle control and/or apoptosis, including p53, p21 waf1/cip1, $\mathrm{Bcl} 2, \mathrm{Bax}, \mathrm{Bcl}-\mathrm{x}_{\mathrm{L}}$ and survivin, only indicates a possible involvement of Bcl- $x_{L}$, which is decreased in MCF7 $\mathrm{Adr}^{\mathrm{R}}$ cells following LIN treatment.

\section{Materials and methods}

Chemicals and reagents. Linalool (LIN) was purchased from Tebu-Bio S.r.1. (Magenta, Italy). 3-(4,5-dimethylthiazol-2-yl)-2,5-diphenyl-tetrazolium bromide (MTT), and standard reagents were purchased from Sigma-Aldrich S.r.l. (Milan, Italy). Doxorubicin (DOX) was kindly provided by Dr A. Suarato (Nerviano Medical Sciences, Nerviano, Italy) and dissolved in water as a $10 \mathrm{mM}$ stock solution.

Cells and in vitro culture conditions. MCF7 WT cells, obtained from ATCC (Manassas, VA) and MCF7 $\mathrm{Adr}^{\mathrm{R}}$ cells, the MDR variant of MCF7 WT selected for resistance to DOX and kindly provided by Dr K. Cowan (University of Nebraska Medical Center), were cultured in DMEM medium, supplemented with $10 \%$ fetal bovine serum, $1 \%$ glutamine and $1 \%$ antibiotics mixture at $37^{\circ} \mathrm{C}$ under $5 \% \mathrm{CO}_{2}$.

Cytotoxicity studies. The antiproliferative effects of DOX, LIN and their combinations were assessed in human breast adenocarcinoma MCF7 WT and MCF7 Adr ${ }^{\mathrm{R}}$ cells by the MTT assay (29). Briefly, cells were seeded onto 96-well plates, allowed to attach and grow for $24 \mathrm{~h}$ and subsequently exposed to different DOX concentrations $(0.05-10 \mu \mathrm{M}$ for MCF7 WT cells; $1-250 \mu \mathrm{M}$ for MCF7 $\mathrm{Adr}^{\mathrm{R}}$ cells) in the presence or absence of fixed subtoxic LIN concentrations (10 and $50 \mu \mathrm{M})$ for $72 \mathrm{~h}$. At the end of the treatment, MTT $(2 \mathrm{mg} / \mathrm{ml}$ in PBS) was added for $3 \mathrm{~h}$ at $37^{\circ} \mathrm{C}$; formazan crystals, formed by mitochondrial reduction of MTT, were solubilized in DMSO and the absorbance was read at $570 \mathrm{~nm}$, using a Universal
Microplate reader EL800 (Bio-Tek Instruments, Winooski, VT).

$\mathrm{IC}_{50}$ values were calculated by the median effect equation; differences between $\mathrm{IC}_{50}$ values were analyzed statistically by two-way analysis of variance with Bonferroni post-test for multiple comparisons, using Prism 3.03 (GraphPad Software, Inc.). The interaction between LIN and DOX was analyzed using the CalcuSyn software (Biosoft Cambridge, MA), based on the method described by Chou \& Talalay (30). According to this method, a combination index (CI) can be calculated from dose-response curves obtained following exposure to DOX and/or LIN as single agents and in combination. CI values approximating 1.0 indicate additive interactions between the two agents; $\mathrm{CI}<1.0$ indicates synergy and, conversely, CI>1.0 indicates antagonism.

Flow cytometric studies. The induction of apoptotic cell death and the effect on cell cycle distribution by $24 \mathrm{~h}$ exposure to LIN $(50 \mu \mathrm{M})$ were evaluated by flow cytometry. Cells exposed to LIN were detached by trypsinization, washed in phosphate-buffered saline (PBS) and fixed in ice-cold $70 \%$ ethanol for $20 \mathrm{~min}$ at $-20^{\circ} \mathrm{C}$. After a further wash in PBS, DNA was stained with $50 \mu \mathrm{g} / \mathrm{ml}$ propidium iodide in PBS in the presence of RNAse $\mathrm{A}(30 \mathrm{U} / \mathrm{ml})$ at $37^{\circ} \mathrm{C}$ for $30 \mathrm{~min}$.

Accumulation studies were also performed by flow cytometry, following $24 \mathrm{~h}$ pretreatment of MCF7 WT and MCF7 $\mathrm{Adr}^{\mathrm{R}}$ with $50 \mu \mathrm{M}$ LIN; $10 \mu \mathrm{M}$ DOX was added for the last $2 \mathrm{~h}$ of incubation. At the end of the treatment period, the cells were rapidly washed with ice-cold PBS, detached with EDTA and trypsin, resuspended in ice-cold PBS and analyzed.

All samples were analyzed with a FACScan flow cytometer (Becton-Dickinson Mountain View, CA) equipped with a $15 \mathrm{~mW}, 488 \mathrm{~nm}$, and an air-cooled argon ion laser. Fluorescent emissions were collected through a $575 \mathrm{~nm}$ band-pass filter, both for DOX or PI, and acquired in $\log$ mode. At least 10,000 events were analyzed for each sample. The percentage of apoptotic cells in each sample was determined based on the sub-G1 peaks detected in monoparametric histograms; for DOX accumulation studies, fluorescence intensity was expressed as mean fluorescence channel (MFC) calculated from the flow cytometric profiles by the CellQuest software (Becton-Dickinson).

Immunodetection of p53, p21, Bcl2, Bax, Bcl- $x_{L}$ and survivin. MCF7 WT and MCF7 $\mathrm{Adr}^{\mathrm{R}}$ cells were exposed to $50 \mu \mathrm{M}$ LIN for $24 \mathrm{~h}$ and protein extracts were obtained. In most cases $30 \mu \mathrm{g}$ of protein per lane were loaded onto polyacrylamide gels (11\%) and separated under denaturing conditions; only in the case of $\mathrm{Bcl} 2$ immunodetection $150 \mu \mathrm{g}$ of protein were loaded (instead of the usual 30). Protein bands were then transferred onto Immobilon $\mathrm{P}$ membranes (Millipore, Bedford, MA, USA), and Western blot analysis was performed by standard techniques with the following antibodies: mouse monoclonal anti-human $\mathrm{Bcl} 2$ (100) and anti-p53 (DO-1); rabbit polyclonal anti-human Bax (N-20), rabbit monoclonal anti-human p21 (C-19) (Santa Cruz Biotechnology, Inc., Santa Cruz, CA, USA); mouse monoclonal antiBcl- $\mathrm{X}_{\mathrm{L}}$ (MBL Co., Japan); rabbit polyclonal anti-survivin (Abcam, Cambridge, UK). Protein bands were visualized 
Table I. Cytotoxic effects of DOX (72 h), as a single agent or in combination with subtoxic concentrations of LIN, on MCF7 WT and MCF7 $\mathrm{Adr}^{\mathrm{R}}$ cells (mean $\pm \mathrm{SE}$ of 4 independent experiments). CI, combination index (see text).

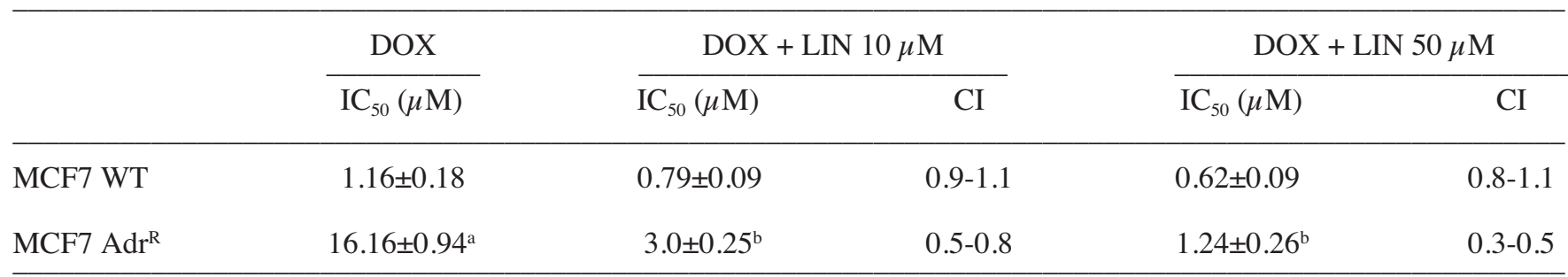

${ }^{\mathrm{a}} \mathrm{p}<0.05$ vs MCF7 WT; ${ }^{\mathrm{b}} \mathrm{p}<0.05$ vs DOX.

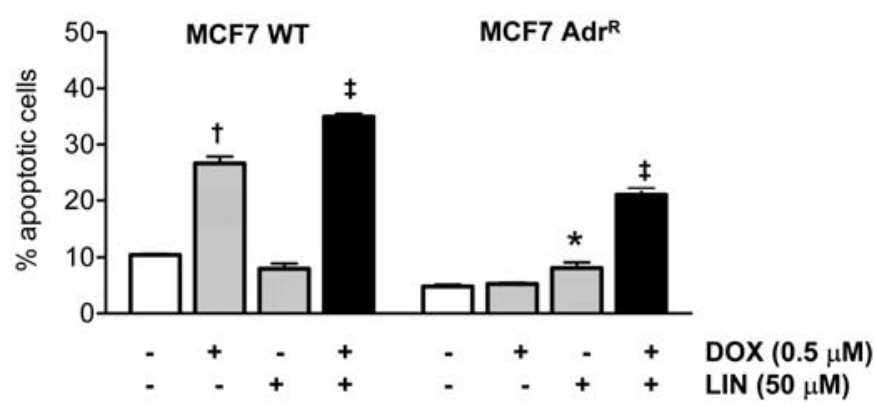

Figure 2. Induction of apoptosis in MCF7 WT and MCF7 Adr ${ }^{\mathrm{R}}$ cells following $24 \mathrm{~h}$ exposure to $\operatorname{DOX}(0.5 \mu \mathrm{M})$ and/or LIN $(50 \mu \mathrm{M})$. Mean \pm SEM of three independent experiments. ${ }^{*} \mathrm{p}<0.05$ vs. control; ${ }^{\dagger} \mathrm{p}<0.001$ vs. control; ${ }^{\ddagger} \mathrm{p}<0.001$ vs. control and vs. DOX.

using a peroxidase-conjugated anti-mouse/rabbit secondary antibody and the Supersignal West Pico Chemiluminescence Substrate (Pierce, Milan).

\section{Results}

Cytotoxicity studies. As a single agent, LIN only exerts weak antiproliferative effects against MCF7 WT and MCF7 Adr ${ }^{\mathrm{R}}$ cells, yielding $\mathrm{IC}_{50}$ values of $200.48 \pm 48.31 \mu \mathrm{M}$ and $128.26 \pm 19.95 \mu \mathrm{M}$ (mean $\pm \mathrm{SE}$ of 4 independent experiments), respectively; the outcome is not significantly affected by the presence of a typical MDR phenotype. Table I reports the $\mathrm{IC}_{50}$ values extrapolated from the dose-response curves obtained in MCF7 WT and MCF7 Adr ${ }^{\mathrm{R}}$ cells following $72 \mathrm{~h}$ treatment with increasing concentrations of DOX in the presence or absence of two subtoxic concentrations of LIN $(10$ and $50 \mu \mathrm{M})$. As expected, MCF7 $\mathrm{Adr}^{\mathrm{R}}$ cells were more resistant to DOX than MCF7 WT cells. The results obtained with the LIN/DOX combinations indicate that LIN increases the cytotoxicity of DOX in a dose-dependent fashion in both cell lines; CI values (also reported in Table I) indicate a significant synergistic effect between DOX and LIN in MCF7 $\mathrm{Adr}^{\mathrm{R}}$ for both LIN concentrations, whereas in MCF7 WT cells an additive interaction was observed between the two compounds.

Apoptosis detection. Fig. 2 shows the percentage of apoptotic cells obtained by flow cytometric analysis of MCF7 WT and

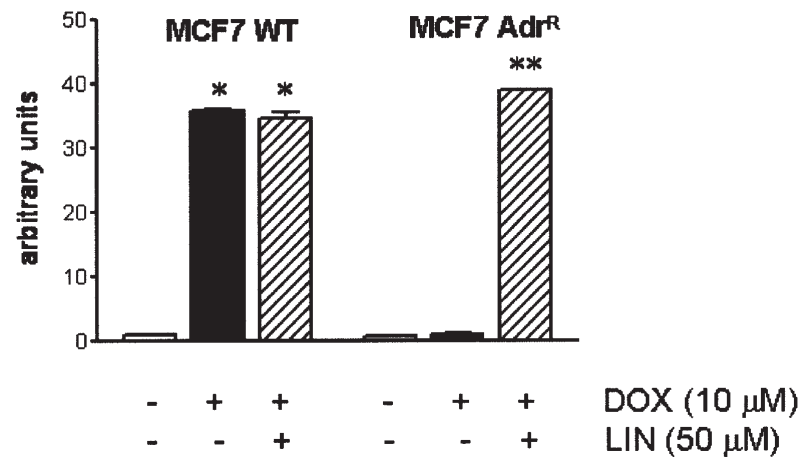

Figure 3. Intracellular accumulation of DOX (10 $\mu \mathrm{M}$ for $2 \mathrm{~h})$ in MCF7 WT and MCF7 $\mathrm{Adr}^{\mathrm{R}}$ cells following $24 \mathrm{~h}$ exposure to LIN $(50 \mu \mathrm{M})$. Mean \pm SEM of three independent experiments. ${ }^{*} \mathrm{p}<0.001$ vs. control; ${ }^{* *} \mathrm{p}<0.001$ vs. control and DOX alone.

MCF7 $\mathrm{Adr}^{\mathrm{R}}$ cells following $24 \mathrm{~h}$ exposure to DOX $(0.5 \mu \mathrm{M})$ and LIN $(50 \mu \mathrm{M})$ as single agents or in combination. Again as expected, the parental cell line was more sensitive to the pro-apoptotic effect of DOX than the multidrug resistant variant. No significant increase in apoptosis induction over control values was observed in either cell lines when LIN was used as a single agent. When DOX and LIN were combined, a significant increase in the percentage of apoptotic cells was observed in both cell lines as compared both to control values and to the values obtained with the two compounds as single agents.

Cell cycle analysis. The effects of LIN (50 $\mu \mathrm{M}$ for $24 \mathrm{~h})$, both as a single agent and in combination with $\operatorname{DOX}(0.5 \mu \mathrm{M})$, on cell cycle distribution of MCF7 WT and MCF7 Adr ${ }^{\mathrm{R}}$ cells are reported in Fig. 5. In both cell lines 24 h exposure to LIN or DOX as single agents induces an increase in the G2/M and a decrease in the G1 phase cell subpopulations. In MCF7 WT cells, simultaneous exposure to DOX and LIN results in a decrease in the percentage of cells in the G1 phase, while in MCF7 $\mathrm{Adr}^{\mathrm{R}}$ cell line a relevant increase in the G2/M cell subpopulation and a parallel decrease in $\mathrm{G} 1$ cells can be observed.

Effect of LIN on DOX accumulation. Fig. 3 shows the results obtained by flow cytometric analysis of intracellular DOX levels in MCF7 WT and MCF7 Adr ${ }^{\mathrm{R}}$ cells following exposure 


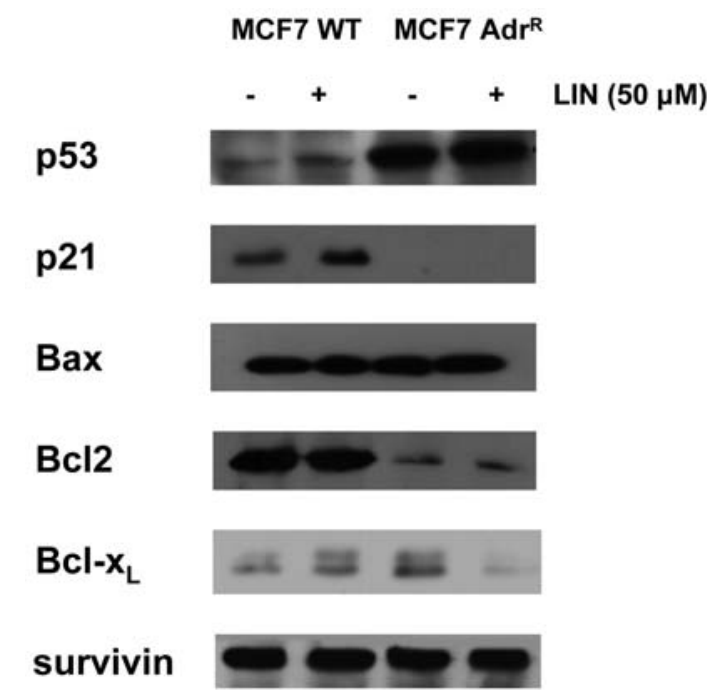

Figure 4. Effect of $24 \mathrm{~h}$ exposure to LIN $(50 \mu \mathrm{M})$ on p53, p21, Bax, Bcl2, Bcl- $\mathrm{x}_{\mathrm{L}}$ and survivin protein levels in MCF7 WT and MCF7 $\mathrm{Adr}^{\mathrm{R}}$ cells.

to $10 \mu \mathrm{M}$ DOX for $2 \mathrm{~h}$. Pretreatment with a subtoxic concentration of LIN $(50 \mu \mathrm{M})$ for $24 \mathrm{~h}$ (including simultaneous exposure to the two agents for the last $2 \mathrm{~h}$ ) induces a significant increase in DOX accumulation in MCF7 $\mathrm{Adr}^{\mathrm{R}}$ cells as compared to cells exposed to the anthracycline alone. In contrast, the amount of DOX detected in MCF7 WT cells is not significantly affected by LIN treatment.

Expression of p53, p21, Bcl2, Bax, Bcl- $x_{L}$ and survivin. Fig. 4 shows the effect of $50 \mu \mathrm{M}$ LIN for $24 \mathrm{~h}$ on the intracellular levels of p53, Bax, Bcl2, Bcl- $\mathrm{x}_{\mathrm{L}}$, survivin and p21 in MCF7 WT and MCF7 Adr ${ }^{R}$ cells. As expected, MCF7 Adr ${ }^{R}$ cells, that harbor a mutant form of the gene, exhibit higher p53 levels than MCF7 WT cells, with a wild-type p53 gene. LIN treatment induces a modest increase of p53 levels in MCF7 $A d r^{R}$ cells, while protein expression is unaffected in MCF7 WT cells. p21 levels can only be detected in MCF7 WT and are unmodified following LIN exposure. Both cell lines express similar levels of Bax and survivin, which are not affected by treatment with LIN. Bcl2 levels are significantly higher in the parental than in the resistant cell line, but are not affected by LIN treatment. In contrast, $\mathrm{Bcl}-\mathrm{x}_{\mathrm{L}}$ is present at higher levels in MCF7 $\mathrm{Adr}^{\mathrm{R}}$ than in MCF7 WT cells; interestingly, $24 \mathrm{~h}$ exposure to LIN induces a decrease in $\mathrm{Bcl}-\mathrm{x}_{\mathrm{L}}$ in the resistant cell line, whereas in the parental cell line a slight increase can be observed.

\section{Discussion}

Monoterpenes are non-nutritive dietary components found in the essential oils of citrus fruits, mint and herbs and they are largely responsible for the distinctive fragrance of these plants. A number of dietary monoterpenes, such as $d$-limonene, carvone and perillyl alcohol, have shown antitumor activity in different experimental models, including breast cancer, exhibiting not only the ability to prevent the formation or progression of cancer, but to induce the regression of existing

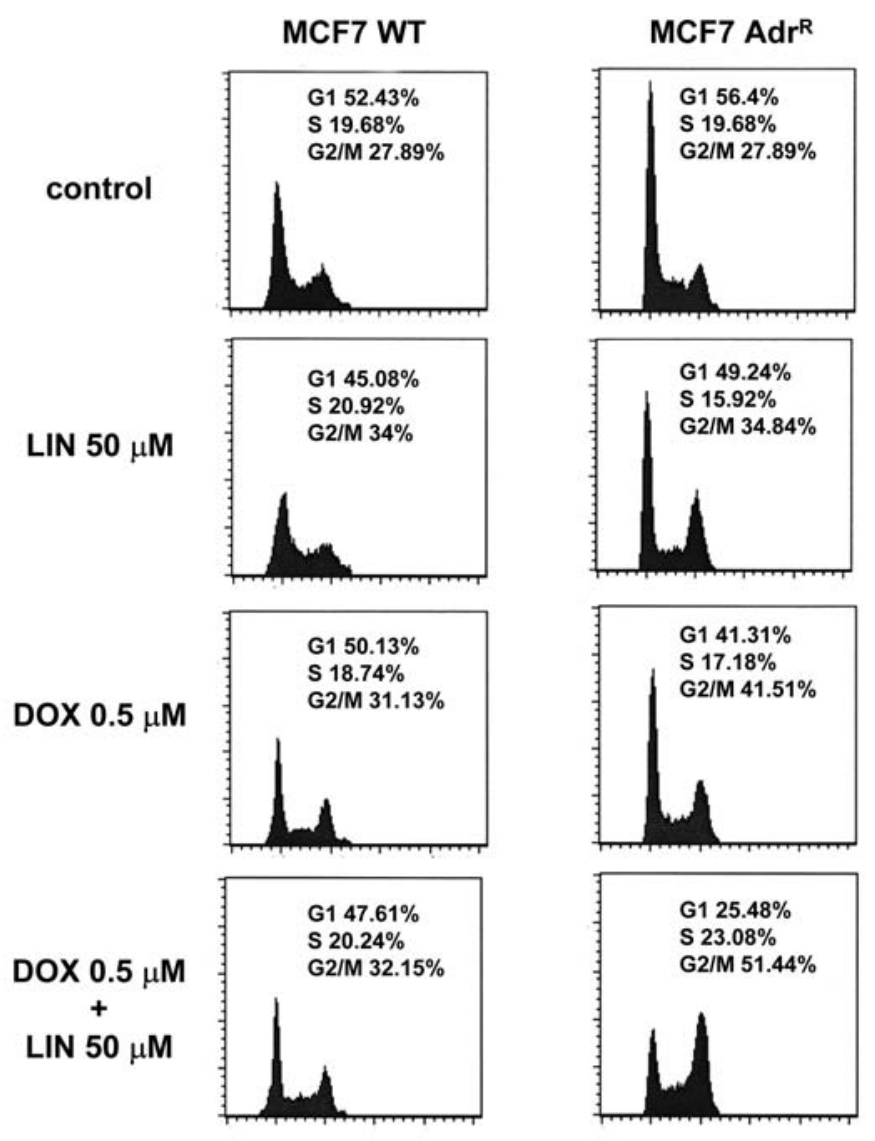

Figure 5. Effect of $24 \mathrm{~h}$ exposure to LIN $(50 \mu \mathrm{M})$ and DOX $(0.5 \mu \mathrm{M})$, as single agents or in combination, on the cell cycle distribution of MCF7 WT and MCF7 $\mathrm{Adr}^{\mathrm{R}}$ cells.

malignant tumors, likely by more than one molecular mechanism (21-23,31-33). Accordingly, both limonene and perillyl alcohol have progressed into clinical trials. However, results from phase II trials with these compounds in patients with advanced solid tumors have been disappointing so far (34,36,37).

A number of reports indicating the ability of herbs and their components to interfere with drug transporters (38) suggest a different application for monoterpenes in the management of neoplastic disease, i.e. a possible use as chemosensitizers; however, this issue has not received much attention to date (14).

In the present study, we show that the monoterpene alcohol LIN has indeed the ability to sensitize human breast cancer cells, and particularly those exhibiting a Pgp-mediated resistant phenotype, to the cytotoxic activity of DOX. Currently available data on the chemopreventive and chemotherapeutic potential of LIN are somewhat controversial (24-26). The results obtained in our studies using LIN as a single agent are in agreement with the observation reported by Kubo and Morimitsu (23), indicating that LIN has a very weak antiproliferative effect on breast cancer cells. Interestingly, however, when subtoxic concentrations of LIN are combined with DOX, the cytotoxic activity of the anthracycline is synergistically increased in the multidrug resistant cell line; in the parental cell line a dose-dependent decrease in the $\mathrm{IC}_{50}$ of DOX can be observed with increasing LIN 
concentrations, but this effect does not attain statistical significance, and the calculated CI values indicate that the interaction between the two compounds is additive at best. These results are supported by data on apoptosis induction by DOX in the two cell lines: again, simultaneous exposure to LIN $(50 \mu \mathrm{M})$, which per se does not increase the percentage of apoptotic cells above control values, significantly potentiates the effect of $0.5 \mu \mathrm{M}$ DOX in $24 \mathrm{~h}$; however, in this case a significant increase is observed in MCF7 WT as well as in MCF7 Adr $^{R}$ cells. The increase in G2/M phase, observed when cells were simultaneously exposed to LIN and DOX, indicates a premature entry into M-phase and might explain the decrease in cell viability and the increase in apoptosis induction observed in both cell lines.

The relevance of these observations should be discussed in the context of the potential clinical application of LIN as a chemosensitizing agent. As a result of its wide use as a food additive and as a fragrance ingredient in cosmetics and detergents, a wealth of toxicological data are available on this compound (12) indicating that exposure by different routes is substantially safe. In contrast, pharmacokinetic data are scarce, and only concern transdermal and inhalationdependent routes, whereas, to our knowledge, no studies have been published following oral or intraperitoneal administration (35). However, the available data concur to suggest that chemosensitizing LIN levels can be achieved in plasma following dermal application or inhalation without undue systemic toxicity.

To explain the synergy between LIN and DOX in MCF7 cells, we first assessed the effect of LIN on intracellular DOX accumulation. This approach was suggested by the observation that MCF7 $\mathrm{Adr}^{\mathrm{R}}$ cells, which are known to accumulate lower drug amounts due to overexpression of the Pgp efflux pump, are also more susceptible to the chemosensitizing effect of LIN. Flow cytometric data showed significantly lower levels of DOX in MCF7 $\mathrm{Adr}^{\mathrm{R}}$ than in MCF7 WT cells, as expected, and pretreatment with LIN was able to restore DOX accumulation in the resistant cells, while drug levels were unaffected in the parental cell line. These data suggest the hypothesis that LIN interferes with DOX transport mechanisms that are overexpressed in the resistant cell line and Pgp is a logical candidate target for LIN action, even though this point was not specifically addressed in this preliminary study. However, this is probably not the only mechanism involved in the LIN/DOX interaction: in fact, LIN was able to increase apoptosis induction by DOX not only in the resistant, but in the parental cell line as well. Therefore we also examined the effects of LIN on the intracellular levels of a small panel of proteins controlling the cell cycle and/or apoptotic pathways. Western blot analysis of protein extracts from both cell lines did not show relevant alterations in the protein levels of p53, p21 waf1/cip1, Bax, Bcl2 and survivin following LIN exposure for $24 \mathrm{~h}$. On the other hand, the results obtained for $\mathrm{Bcl}-\mathrm{x}_{\mathrm{L}}$ were somewhat unexpected, with an evident down-regulation of this protein by LIN in MCF7 Adr ${ }^{\mathrm{R}}$ cells, which could account for the proapoptotic outcome observed in this cell line, but a slight upregulation of the same in MCF7 WT cells, which is in contrast with the observed potentiation of DOX-induced apoptosis.
To conclude, the studies presented here on the LIN/DOX combination in breast cancer cells appear to support LIN as a chemosensitizing agent, particularly in MDR cells; further studies will be required to explore and explain the mechanistic basis of this interaction.

\section{References}

1. Craig WJ: Health-promoting properties of common herbs. Am J Clin Nutr 70: 491S-499S,1999.

2. Surh YJ: Cancer chemoprevention with dietary phytochemicals. Nature 3: 768-780, 2003.

3. Buhagiar JA, Podesta MT, Wilson AP, Michallef MJ and Ali S: The induction of apoptosis in human melanoma, breast and ovarian cancer cell lines using an essential oil extract from the conifer Tetraclinis articulata. Anticancer Res 19: 5435-5443, 1999.

4. Paik SY, Kho KH, Beak SM, Paek SH and Kim JA: The essential oils from Zanthoxylum schinifolium pericarp induce apoptosis of HepG2 human hepatoma cells through increased production of reactive oxygen species. Biol Pharm Bull 28: 802-807, 2005.

5. D'Incalci M, Steward W and Gescher A: Use of cancer chemopreventive phytochemicals as antineoplastic agents. Lancet Oncol 6: 899-904, 2005.

6. Howells LM and Manson MM: Prospects for plant-derived chemopreventive agents exhibiting multiple mechanisms of action. Curr Med Chem Anticancer Agents 5: 201-213, 2005

7. Gottesman MM and Pastan I: Biochemistry of multidrug resistance mediated by the multidrug transporter. Annu Rev Biochem 62: 3385-3427, 1993

8. Arora A, Seth K, Kalra N and Sukla Y: Modulation of Pglycoprotein-mediated multidrug resistance in K562 leukemic cells by indole-3-carbinol. Toxicol Appl Pharmacol 202: 237-243, 2005.

9. Limtrakul P, Chearwae W, Shukla S, Phisalphong C and Ambudkar SV: Modulation of function of three ABC drug transporters, P-glycoprotein (ABCB1), mitoxantrone resistance protein $(\mathrm{ABCG})$ and multidrug resistance protein 1 (ABCC1) by tetrahydrocurcumin, a major metabolite of curcumin. Mol Cell Biochem 296: 85-95, 2007.

10. Jodoin J, Demeule M and Beliveau R: Inhibition of the multidrug resistance P-glycoprotein activity by green tea polyphenols. Biochim Biophys Acta 1542: 149-159, 2002.

11. Todd WA and Murray MJ: New essential oils from hybridization of Mentha citrata Ehrh. Perfumery Essent Oil Record 59: 97-102, 1968.

12. Letizia CS, Cocchiara J, Lalko J and Api AM: Fragrance material review on linalool. Food Chem Toxicol 41: 943-964, 2003.

13. Kubo I, Muroi H and Himejima M: Antimicrobial activity of green tea flavor components and their combination effects. J Agric Food Chem 40: 245-248, 1992.

14. Mazzanti G, Battinelli G and Salvatore G: Antimicrobial properties of the linalool-rich essential oil of Hyssopus officinalis L. var. decumbens (Lamiaceae). Flav Fragr J 13: 289-294, 1998.

15. Do Socorro S, Rosa Mdo S, Mendonca-Filho RR, Bizzo HR, De Almeida Rodrigues I, Soares RM, Souto-Padron T, Alviano CS and Lopes AH: Antileishmanial activity of a linalool-rich essential oil from Croton cajucara. Antimicrob Agents Chemother 47: 1895-1901, 2003.

16. Chiang LC, Ng LT, Cheng PW, Chiang W and Lin CC: Antiviral activities of extracts and selected pure constituents of Ocimum basilicum. Clin Exp Pharmacol Physiol 32: 811-816, 2005.

17. Peana AT, D'Aquila PS, Panin F, Serra G, Pippia P and Moretti MDL: Anti-inflammatory activity of linalool and linalyl acetate constituents of essential oils. Phytomedicine 9: 721-726, 2002.

18. Peana AT, D'Aquila PS, Chessa ML, Moretti MD, Serra G and Pippia P: (-)-Linalool produces antinociception in two experimental models of pain. Eur J Pharmacol 460: 37-41, 2003.

19. Ghelardini C, Galeotti N, Salvatore G and Mazzanti G: Local anaesthetic activity of the essential oil of Lavandula angustifolia. Planta Med 65: 700-703, 1999. 
20. Edris AE: Pharmaceutical and therapeutic potentials of essential oils and their individual volatile constituents: a review. Phytother Res 21: 308-323, 2007.

21. Crowell PL: Prevention and therapy of cancer by dietary monoterpenes. J Nutr 129: 775S-778S, 1999.

22. Bardon S, Picard K and Martel P: Monoterpenes inhibit cell growth, cell cycle progression, and cyclin D1 gene expression in human breast cancer cell lines. Nutr Cancer 32: 1-7, 1998.

23. Kubo I and Morimitsu Y: Cytotoxicity of green tea flavor compounds against two solid tumor cells. J Agric Food Chem 43: 1626-1628, 1995.

24. Cherng J-M, Shieh D-E, Chiang W, Chang M-Y and Chiang L-C: Chemopreventive effects of minor dietary constituents in common foods on human cancer cells. Biosci Biotechnol Biochem 71: 1500-1504, 2007.

25. Chiang LC, Chiang W, Chang MY, Ng LT and Lin CC: Antileukemic activity of selected natural products in Taiwan. Am J Chin Med 31: 37-46, 2003.

26. Fairchild CR, Ivy SP, Kao-Shan CS, Whang-Peng J, Rosen N, Israel MA, Melera W, Cowan KH and Goldsmith ME: Isolation of amplified and overexpressed DNA sequences from adriamycinresistant human breast cancer cells. Cancer Res 47: 5141-5148, 1987.

27. Cowan KH, Batist G, Tulpule A, Sinha BK and Myers CE: Similar biochemical changes associated with multidrug resistance in human breast cancer cells and carcinogen-induced resistance to xenobiotics in rats. Proc Natl Acad Sci USA 83: 9328-9332, 1986

28. Scudiero DA, Shoemaker RH, Paull KD, Monks A, Tierney S, Nofziger TH, Currens MJ, Seniff D and Boyd MR: Evaluation of a soluble tetrazolium/formazan assay for cell growth and drug sensitivity in culture using human and other tumor cell lines, Cancer Res 48: 4827-4833, 1988.

29. Chou TC and Talalay P: Quantitative analysis of dose-effect relationships: the combined effects of multiple drugs or enzyme inhibitors. Adv Enzyme Regul 22: 27-55, 1984.
30. Crowell PL: Monoterpenes in breast cancer chemoprevention. Breast Cancer Res Treat 46: 191-197, 1997.

31. Shi W and Gould MN: Induction of cytostasis in mammary carcinoma cells treated with the anticancer agent perillyl alcohol Carcinogenesis 23: 131-142, 2002.

32. Bardon S, Foussard V, Fournel S and Loubat A: Monoterpenes inhibit proliferation of human colon cancer cells by modulating cell cycle-related protein expression. Cancer Lett 181: 187-194, 2002.

33. Vigushin DM, Poon G, Boddy A, English J, Halbert GW, Pagonis C, Jarman M and Coombes RC: Phase I and pharmacokinetic study of D-limonene in patients with advanced cancer. Cancer Chemother Pharmacol 42: 111-117, 1998.

34. Bailey HH, Levy D, Harris LS, Schink JC, Foss F, Beatty P and Wadler S: A phase II trial of daily perillyl alcohol in patients with advanced ovarian cancer: Eastern Cooperative Oncology Group Study E2E96. Gynecol Oncol 85: 464-468, 2002.

35. Meadows SM, Mulkerin D, Berlin J, Bailey H, Kolesar J, Warren D and Thomas JP: Phase II trial of perillyl alcohol in patients with metastatic colorectal cancer. Int J Gastrointest Cancer 32: 125-128, 2002.

36. Yang XX, Hu ZP, Duan W, Zhu YZ and Zhou SF: Drug-herb interactions: eliminating toxicity with hard drug design. Curr Pharm Des 12: 4649-4664, 2006.

37. Yoshida N, Takagi A, Kitazawa H, Kawakami J and Adachi I: Inhibition of P-glycoprotein-mediated transport by extracts of and monoterpenoids contained in Zanthoxyli fructus. Toxicol Appl Pharmacol 209: 167-173, 2005.

38. Bickers D, Calow P, Greim H, Hanifin JM, Rogers AE, Saurat AE, Sipes IG, Smith RL and Tagami H: A toxicologic and dermatologic assessment of linalool and related esters when used as fragrance ingredients. Food Chem Toxicol 41: 919-942, 2003. 